\title{
A TEORIA/CONCEPÇÃO SISTÊMICA: UMA PERSPECTIVA CRÍTICA NA PEDAGOGIA DE EDUCAÇÃO FÍSICA?
}

\author{
Marcelo Guina FerreirA*
}

\section{RESUMO}

Inicialmente pensado para ser uma resenha do livro Educação Física e sociedade, em que encontramos parte essencial da construção teórica da chamada concepção sistêmica de educação física, este artigo amplia seus limites e dialoga com algumas outras produções no âmbito desta que pretende ser uma 'sociologia (sistêmica) da educação física'. Nossas considerações se direcionam para aspectos epistemológicos, políticos e pedagógicos desta teoria. Argumentamos que: a) ela aponta elementos metodológicos que contribuem com o discurso crítico em EF; b) encontra-se atravessada tanto por pressupostos que identificam o discurso crítico quanto por aqueles que demarcam uma postura conservadora; c) uma perspectiva sociológica com base na teoria dos sistemas possui fatores limitantes para o desenvolvimento de algo como uma uma 'sociologia da EF'.

PALAVRAS-CHAVE: concepção sistêmica, sociologia, educação física.

\section{INTRODUÇÃO}

os últimos anos pudemos perceber uma forte presença, no cenário
da produção do conhecimento em Educação Física (EF), de estudos voltados para o desenvolvimento de uma teoria ou pedagogia da EF. Em outra oportunidade (Ferreira,1995) apresentamos uma breve síntese do atual quadro de desenvolvimento da teoria da EF brasileira, localizando algumas de suas principais abordagens e respectivas problemáticas investigadas, impasses e perspectivas. Neste contexto surgiu a necessidade de dispensarmos uma maior atenção para o estudo detalhado de cada teoria ou pedagogia da EF. Com este intuito resenhamos algumas das propostas que, em nosso julgamento, representam (mas não esgotam) o atual estágio da teoria da EF no país. Entre elas encontra-se a assim chamada teoria ou concepção sistêmica da EF (Betti,1991), da qual nos ocuparemos no presente artigo.

\footnotetext{
* Professor da Faculdade de Educação Física da UFG.
}

36 Ferreira, M. G. - A teoria/concepção sistêmica: uma perspectiva ... 
Inicialmente a intenção era produzir uma resenha do livro Educação Física e Sociedade, de autoria do Prof. Mauro Betti, que contém o arcabouço teórico-metodológico essencial desta concepção ou teoria sistêmica da EF. De fato, os leitores encontrarão aqui tal resenha, todavia, fomos além e optamos por incluir, no corpo da presente análise, outros textos e artigos do Prof. Betti por julgar que eles ajudam a ampliar a compreensão de tal concepção. Com isto, este texto perde o caráter mais formal de resenha de um livro e se permite a abranger um conjunto de elementos outros, que nos possibilite não apenas uma interpretação mais integrada dos fundamentos centrais da concepção sistêmica, como também, exatamente por isto, sua crítica igualmente mais articulada.

O texto inicia com uma síntese da obra EF e sociedade, em seguida apresenta uma análise crítica de seus pressupostos, ao mesmo tempo em que analisa outras produções teóricas no âmbito da teoria sistêmica da EF. Basicamente nossas considerações se dividem em três principais eixos de reflexão: a) epistemológico; b) político-ideológico e c) pedagógico-educacional. Por fim, buscamos evidenciar que a teoria da EF em tela: a) de fato aponta elementos metodológicos alternativos, visando a contribuir com o discurso crítico em EF; b) encontra-se atravessada tanto por pressupostos que identificam o discurso crítico quanto por aqueles que demarcam uma postura epistemológica, política e pedagógica conservadora; e c) possui na perspectiva sociológica, assumida com base na teoria dos sistemas, fatores limitantes para um desenvolvimento mais efetivo de uma sociologia da EF.

\section{TEORIA/CONCEPÇÃO SISTÊMICA: BREVE SÍNTESE OU... PREPARANDO O DEBATE E A POLÊMICA}

Como as decisões tomadas no ensino da Educação Física (EF) relacionam-se a interesses contidos na política educacional de determinado contexto histórico, expressando uma dada relação escola-sociedade? Como tais opções objetivam-se no trinômio professor-aluno-conteúdo, influenciando a formação de certa concepção de homem? Enfim, como a dinâmica social interna da prática pedagógica em EF vincula-se a objetivos educacionais estabelecidos historicamente?

Pode-se dizer que tais indagações constituem o núcleo da problemática, objeto da investigação, do professor Mauro Betti. Mais especifi- 
camente, sua preocupação volta-se para discursos pedagógicos críticos na EF que, a partir de meados dos anos 80, conseguem substanciais avanços no plano sociofilosófico, mas que ainda não logrou a mesma efetividade em transladar este discurso crítico para a prática pedagógica, ou para o interior do trinômio professor-aluno-matéria de ensino.

Como, então, explicar as opções pedagógicas tomadas no ensino de EF, desde suas primeiras propostas de implantação curricular oficial no Brasil, até a emergência do discurso pedagógico crítico nos anos 80 ? $\mathrm{O}$ autor admite por pressuposto que só o nível sociológico de análise permite uma interpretação destas questões, demonstrando que, de fato, a atuação do professor de EF "se dá numa concretude histórica, sociocultural e econômica que condiciona e é condicionada" (p.11) pela mesma. Por isso, seu estudo trata, fundamentalmente, do desenvolvimento de um modelo sociológico que possibilite responder as indagações já colocadas, e considerando-se o período entre 1930 e 1986. Enfim, trata-se de uma teoria sociológica da EF.

Betti aborda a temática a partir de duas opções teóricometodológicas principais: a) a insatisfação com "paradigmas sociológicos tradicionais" derivados um do positivismo, outro do marxismo, e possibilidades pouco promissoras de "abordagens filosófico-ideológicas" (afastam-se da prática inerente a EF) e do "método empírico reducionista" (reducionista no trato daquela prática) levaram o autor a optar por uma alternativa metodológica: a sociologia segundo a moderna teoria dos sistemas (Buckley apud Betti,1991), na qual um sistema é um conjunto de elementos interagindo; b) a partir desta abordagem a EF é vista como sistema hierárquico aberto. Hierárquico porque interage com níveis superiores de determinação: o macrossocial, o sistema educacional e o escolar que, nesta ordem, influenciam do mais geral para o mais particular, até alcançar a própria EF. Assim, o nível hierárquico mais inferior é o trinômio professor-aluno-conteúdo. O sistema é aberto porque a EF sofre influências do meio social, mas também o influencia.

Portanto, como os elementos deste sistema hierárquico aberto interagiram nos períodos de 1930 a 1986, influenciando opções pedagógicas tomadas na prática pedagógica em EF? Sempre em busca de resposta, Betti realizou investigação histórica que o levou a determinar a seguinte subdivisão: 1930-1945; 1946-1968; 1969-1979 e 1980-1986. 
De 1930 a 1945 a sociedade brasileira vivia um período de consolidação do modelo econômico urbano-industrial, que suplantou o modelo antigo agrário. A política educacional orientava-se então para a "formação da elite política e de recursos humanos de nível médio para a indústria e o comércio" (p.131), com ênfase em valores que exaltavam o nacionalismo e o militarismo. O discurso pedagógico da EF era eminentemente biologicista, de caráter higienista e eugenista. Seus objetivos direcionavam-se para a melhora de "funções orgânicas", "aperfeiçoamento físico" e desenvolvimento de "qualidades morais". O método de ensino prevalecente era o francês.

De 1946 a 1968 o país viveu um período de intenso crescimento industrial, de ideologia desenvolvimentista e relativa democratização política. A política educacional voltava-se para uma "descentralização liberal-democrática" e expansão do ensino público. Por isso, o discurso pedagógico da EF tornou-se "biopsicossocial" com ênfase "no valor educativo do jogo". Seus objetivos visavam à melhoria "fisiológica, psíquica, social e moral". O método prevalecente, por excelência, foi a Ginástica Desportiva Generalizada (MDG).

De 1969 a 1979 o país viveu o período de fechamento e arbítrio sociopolítico pós-64, de acordo com novas exigências de desenvolvimento de seu modelo econômico, alicerçado na doutrina da segurança nacional. A política educacional voltava-se para tais finalidades. Desta forma, o discurso pedagógico da EF vincula-se ao valor "educativo do esporte", cujos objetivos são a iniciação e performance esportiva, tendo a aptidão física como referência central. Aqui não há caracterização de um método, mas sim a total esportivização da EF, esportivização elevada, inclusive, a "razão de estado", i. e., a EF como base da pirâmide esportiva.

De 1980 a 1986 a política educacional passa a ser questionada em seus rumos históricos e finalidades sociais. Surgem propostas de "descentralização e participação como solução para a crise" (p.132), bem como de uma revalorização do papel social da escola. Neste contexto de reabertura política, caracterizada pelo esgotamento do regime tecnoburocrático-militar, o discurso pedagógico da EF adquire contornos críticos, numa busca de transformação social, "pensamento crítico", "criatividade" e "conscientização". Faltaria, entretanto, método ou métodos de ensino que lhe correspondessem de forma mais sistemática e efetiva. 
Como explicar este quadro histórico-social sob a perspectiva sociológica sistêmica, propondo mudanças?

Betti construiu seu modelo explicativo a partir de contribuições da sociologia da educação e do esporte. A primeira contribuiria para o exame das relações entre escola e sociedade, e a segunda para o exame da dinâmica interna da prática de atividades físicas. Com este modelo o autor pretendeu elaborar uma teoria sociológica (sistêmica) da EF, capaz de explicar como, em contextos históricos diversos, as distintas políticas educacionais atribuiam à escola determinado papel social, o que acarretava para a EF determinada inflluência quanto à tomada de opções pedagógicas no trinômio professor-aluno-conteúdo. Ou seja, explicaria como o movimento, a atividade física, através do acionamento de determinados mecanismos sociais no interior daquele trinômio, atenderia a objetivos e valores postulados pela política educacional historicamente estabelecida, configurando certa influência sobre a formação do educando.

Em suma, o modelo é um sistema complexo, hierárquico e aberto, com quatro níveis de hierarquia: a) política educacional: "mecanismo de transposição dos valores e prioridades sociais para o sistema educacional e escolar"; b) escola: "o instrumento de operacionalização da política educacional, que também define o perfil do egresso do sistema"; c) EF: "transpõe a política educacional, os objetivos do sistema escolar e os interesses de outros sistemas sociais para a prática da Educação Física"; d) processo ensino-aprendizagem: "relacionamento do trinômio professor-aluno-matéria de ensino". Betti ressalta ainda que o caráter aberto do sistema se deve não apenas à relação de influência recíproca entre o macrossocial e a EF, mas também entre forças sociais outras que a influenciaram como os sistemas militar (décadas de 30 e 40, sobretudo) e esportivo (a partir dos anos 60-70).

Para completar a caracterização do modelo, Betti o concebe segundo polaridades num continuum cujos extremos envolvem tanto variáveis sociopsicológicas quanto variáveis didático-pedagógicas.Estas seriam relativas: aos conteúdos - formais e não-formais seriam pólos extremos; aos estilos de ensino - do comando à resolução de problemas. Quanto às variáveis sociopsicológicas, a partir de teorias da sociologia do esporte (teoria do jogo-Huizinga, teoria das polaridades de Elias e Duming e modelo de profissionalização de atitudes de Webb), o autor 
destacou: 1) finalidade - trabalho a jogo, refletindo o caráter de tendência de seriedade ou ludicidade das atividades; 2) interação social - competição a cooperação, refletindo a sobrepujança de indivíduos ou grupos sobre outros, ou a associação destes para obtenção de metas comuns; 3) resolução de conflitos - controle externo x interno, exercido por indivíduos externos ao grupo (árbitro, professor etc) ou pelos próprios estudantes; 4) regras - rígidas $x$ flexíveis, envolvendo atividades físicas intitucionalizadas e não permeáveis a adaptações e variações dentro das características e interesses dos participantes, ou atividades adaptadas e modificadas segundo tais interesses e necessidades; 5) profissionalização de atitudes - vitória a honestidade, "refere-se a tendência da atividade de levar o participante a uma atitude de profissionalização ou honestidade. No ponto intermediário deste contínuo encontra-se a busca do desempenho habilidoso (jogar tão bem quanto possível)" (p.144).

Sua metodologia constou basicamente de uma análise das variáveis a partir dos métodos de ensino hegemônicos nos diversos momentos da história da EF brasileira, além de uma identificação entre a dinâmica social presente nestes e os objetivos formativos propostos pela política educacional hegemônica.

Assim, Betti identificou como a inter-relação destas variáveis viabilizava a consecução de determinados objetivos educacionais. Só para exemplificar, veja-se um caso de cada grupo de variáveis. No caso das didático-pedagógicas teríamos, por exemplo, os estilos de ensino: o comando e a resolução de problemas representando extremos. Os discursos hegemônicos na EF utilizaram, até pela influência do militarismo, o comando. Todavia, para os discursos emergentes, a resolução de problemas constituiria alternativa. Nas interações sociais os extremos seriam, competição e cooperação. Por analogia, o discurso crítico deve buscar efetivar o pólo da cooperação. Logo, é sob esta perspectiva que Betti vislumbra alternativas de alteração na dinâmica social interna da prática pedagógica em EF, capaz de viabilizar a formação de um modelo de cidadão crítico, criativo e consciente.

Betti observou que a formalidade dos conteúdos, o ensino por comando, a atividade física identificada com finalidades de trabalho, a rigidez das regras e o controle externo na mediação de conflitos têm prevalecido ao longo da história da EF no país. Assim, para os discursos críticos, uma metodologia do ensino deve pautar-se não apenas no exa- 
me destas variáveis, mas também na compreensão sistêmica da prática pedagógica em EF.

Ao concluir, o autor admite que a ausência de produção de conhecimentos científicos e a conseqüente falta de realimentação da prática foram fatores que retardaram a compreensão da EF como área específica de conhecimento, facilitando a sua instrumentalização para fins diversos, já que dentro do sistema educacional ela tem sido vista como uma mera "atividade" (p.162). Com isto Betti indica a fragilidade do sistema EF que, não devidamente preenchido com suporte teórico-metodológico em bases científicas e pedagógicas, foi/é facilmente preenchido pelos sistemas militar e esportivo que, em contextos históricos distintos, lhe determinaram não apenas conteúdos e métodos, mas também objetivos educacionais de acordo com a política educacional traçada pelas relações de poder predominantes na sociedade.

Betti percebeu, por um lado, uma similaridade entre propostas pedagógicas e modelos de cidadãos desejados pela estrutura socioeconômica, nos períodos de 1930 a 1945 e de 1970 a 1979, períodos históricos também com certa similaridade (Estado Novo e governos militares pós-64). Por outro lado, percebeu que em períodos de "relativa democratização, entre 1946-65 e após 1982, delineou-se um "modelo de homem mais liberal" (p.166). Embora com isto o autor admita que ainda não há elementos suficientes para estabelecermos uma relação direta, do tipo causal, entre macrossistema social e prática pedagógica de EF.

Todavia, seu maior interesse parece ter sido satisfeito com estas análises. Pois, para Betti, por mais que na política educacional global sejam estabelecidos objetivos indicadores de certa concepção de homem a ser atingida, por meio de processos formais de escolarização; as inúmeras mediações pelas quais uma política educacional e seus objetivos historicamente contingentes passam, até alcançar o nível hierárquico mais inferior (o trinômio professor-aluno-matéria de ensino), acarretam consequências tais como: a) o grau de liberdade diminui quanto aos objetivos educacionais que já foram definidos em níveis hieráquicos superiores; b) permanece para o professor certa liberdade no que diz respeito a ativar ou não mecanismos da dinâmica social que se referem, no processo ensino-aprendizagem, aos objetivos traçados em níveis hierárquicos superiores. "Quer dizer, em última análise, o professor detém o poder de implantar ou não muitas das decisões tomadas nos níveis superiores" (p.166). 
Logo, ao professor compete optar segundo suas convicções filosófico-ideológicas, e de acordo com o modelo de polaridades, por variáveis dentro do continuum que acionam a dinâmica social interna da prática pedagógica. Por isso, o discurso sociopolítico

propõe um modelo de personalidade que desenha um homem crítico, criativo e consciente, e os instrumentos disponíveis no processo ensino-aprendizagem para acionar tais propostas são a polarização em torno da ludicidade, controle interno, não-formalidade dos conteúdos, cooperação, flexibilidade das regras, solução de problemas e honestidade. Pode-se prever um esmorecimento deste discurso se não houver percepção suficiente para acionar esta operacionalização (p. 166-67).

Pelo exposto até o momento, Betti conseguiu de fato associar sociologia da educação e do esporte, tendo em vista a construção de um modelo sociológico de caráter sistêmico aplicado à EF. No entanto, tal não se deu sem que, por outro lado, este modelo acarretasse impasses teóricos e/ou questôes problemáticas relacionadas com o desenvolvimento de uma teoria da EF no Brasil. A partir de agora passamos a discutir, ou simplesmente levantar indagações, a respeito de pontos importantes desta abordagem sistêmica.

\section{TEORIA/CONCEPÇÃO SISTÊMICA: ANÁLISE CRÍTICA OU... APENAS COMEÇANDO O DEBATE}

Inicialmente parece-nos relevante discutir a opção de Betti no âmbito epistemológico, explicitando suas possíveis consequiências políticas. Isso decorre do fato de que o autor pretendeu encontrar uma posição de equidistância epistemológica entre uma "utilização superficial do marxismo" e um "positivismo antiquado" (p. 13), i.e., entre o próprio marxismo e o positivismo. Mas não será que tal posição acaba por privilegiar este em detrimento dos postulados daquele? Sim, porque para o positivismo a equidistância, como corolário do princípio da neutralidade, é um pressuposto básico. Para o marxismo, esta posição seria inaceitável, pois o que estaria em jogo são pontos de vista, a partir dos quais se busca compreender uma sociedade historicamente situada, no caso o capitalismo. Um ponto de vista é necessariamente um ponto de vista de 
classe e, sabe-se, a posição de classe é assumida pela teoria marxista (Löwy, 1978). Logo, diante desta busca de uma postura 'alternativa', situada 'entre' os extremos clássicos do marxismo e do positivismo, parece forçoso reconhecer que Betti de fato acabou por privilegiar o segundo, senão vejamos. Para Betti "nenhum paradigma ou metodologia é capaz de desvendar todos os mistérios da organização social humana, mas cada um fornece uma contribuição particular" (p.13). Ora, queremos acreditar que o autor não está propondo algo parecido com os pressupostos da lógica formal, muito comum em certo empirismo positivista, segundo o qual a totalidade é uma soma das partes. Neste caso, cada paradigma ou metodologia explicaria sua porção do real de forma que, para entendê-lo em sua totalidade concreta (para falarmos com Kosik, 1995), seria necessário recorrer a tantas teorias quanto necessário e/ou possível. ${ }^{1}$ Em nossa compreensão, este tipo de postura afasta Betti da tradição comum para uma teoria educacional crítica ou ainda para uma sociologia crítica da educação, conforme Silva (1992). De acordo com Silva, na tradição analítica crítica em pedagogia "é preciso partir de algumas premissas sobre quais são os processos que movem a sociedade, quais as forças que contribuem para sua estabilização ou para sua mudança" (p.53), explicitando ainda relações entre estes processos. E, para Silva, essas são as qualidades das teorias sociais clássicas, como as de Durkheim, Weber, Marx entre outros. Todavia, reconhecer a necessidade de uma teoria da dinâmica social não é o mesmo que optar por uma ou outra. Pois, a partir deste entendimento,

gostaria de sugerir que a análise que Marx faz da sociedade capitalista em $O$ Capital ainda continua, em suas linhas gerais, não apenas válida, no sentido de corresponder ao seu real funcionamento, mas como aquela que encerra maior potencial analítico (Silva, 1992, p 53).

No entanto, sabemos que Betti não opta pelo marxismo e, buscando fugir também ao positivismo, apóia-se em Max Weber e na teoria dos sistemas segundo Buckley (1971). ${ }^{2}$ Assim, a sociedade como sistema é vista como "conjunto de elementos em interação" (Buckley apud Betti, p.17). A sociologia, portanto, dispensaria maior atenção as inter-relações entre atores interindividuais e papéis e instituições sociais, não

Ferreira, M. G. - A teoria/concepção sistêmica: uma perspectiva ... 
dicotomizando indivíduo-sociedade (Betti, p. 17). E, por outro lado, a mudança social seria vista como a capacidade de um sistema "persistir ou desenvolver-se modificando a própria estrutura, às vezes de maneiras fundamentais" (p. 18). Ao passo que, do ponto de vista metodológico, a opção por Weber o fez admitir que valores são úteis para que, em meio à complexidade da cultura na sociedade, possamos escolher aquelas problemáticas que de fato merecem tornar-se alvo de uma investigação, sem que, no entanto, os valores impeçam o próprio desenvolvimento do trabalho de pesquisa, i.e., seu desenvolvimento e conclusões. Tal postura seria necessária em nome de uma "exigência interna de desenvolvimento e autocontrole" da ciência (Bruyne et al., apud Betti, p. 18), pois deve existir "algum tipo de ruptura entre ciência e ideologia" (Betti, p. $18)$.

Quanto à opção do autor pela teoria dos sistemas não apenas podemos manter nossa contraposição de que ela não encerra maior potencial analítico do que a teoria marxista diante das estruturas e da dinâmica social capitalista, como também poderíamos dizer mais, reforçando que isso afasta Betti do campo de uma pedagogia de esquerda. Para Silva (1993a), mesmo diante dos ataques que a teoria marxista, como uma 'metanarrativa totalizante', vem recebendo de autores pós-modernistas, ela permanece, de acordo com Jameson (1994), na condição privilegiada de teoria cujo objeto de estudo são as relações sociais capitalistas, o que a torna indispensável à teoria educacional crítica. Pois nesta

analisamos e teorizamos tendo em vista um projeto cultural de transformações do mundo social existente. Tudo aquilo que aumente nossa compreensão do mundo e da dinâmica social apenas fortalece uma tradição assim politicamente engajada. (Silva, 1993a, p. 138)

Assim, a teoria dos sistemas afasta Betti desta tradição pedagógica crítica e engajada, posto que em seu modelo parece não haver lugar para a luta de classes, e sim para "interações simbólicas" (p. 18), nem também para a idéia de revolução social, e sim para uma mudança social na qual "a sociedade responde às necessidades de mudança, adaptando sua estrutura e reequilibrando-se num nível mais elevado de complexidade" (p. 133). Aqui é esclarecedor citar Mészaros (1993, p. 29), que em crítica a Weber, afirma: 
A definição [de Weber] tomada como um todo constitui um modelo completamente estático. [...] a eliminação do inter-relacionamento fundamental entre o capital e o trabalho [...] exclui todo dinamismo do cenário. Assim, [...] não haverá espaço para uma possível dissolução substituição derradeira do capitalismo por um novo tipo de formação social. Não haverá vestígios de contradições dinâmicas no modelo; portanto, ele pode apenas abarcar as características estáveis da continuidade - desprezando completamente a dialética da descontinuidade - de um status quo prevalecente.

Com efeito, para Loureiro e Della Fonte (1996), a postura da teoria dos sistemas assumida por Betti na sua obra - que eles analisaram e criticaram do ponto de vista historiográfico - revela uma visão em que,

a cada oscilação ou flutuação para pólos de extremidades conflitantes, o sistema receberia uma informação e se readaptaria, mesmo que só temporariamente. O conflito, portanto, seria regulável e controlável por excelência, sem que isso implicasse na destruiçào dosopostos; eles continuando existindo num nível ótimo permitindo que o sistema continue viável (p. 182)

Ainda com relação à sua opção metodológica apoiada em Max Weber, Betti alinha-se com uma postura que dicotomiza fato e valor. $\mathrm{Na}$ teia complexa dos fenômenos da cultura serão valores que ajudarão a escolher objetos de estudo (Weber apud Betti, p. 16), resguardada a devida área de isenção ou ruptura entre ciência e ideologia como proposto pelo autor. No entanto, de acordo com Löwy (1979), "na problemática já está, em boa medida, definido o conteúdo mesmo da investigação científica e o tipo de resposta possível" (p. 53). Ou seja, há sempre um ponto de vista a partir do qual inquirimos a realidade, e isto condiciona a resposta que ela nos dará, posto que não há fatos dados aos quais ascendemos por um simples processo de observação, como supõe o empirismo. Fatos são teórico-dependentes, i.e., são construções sociais (aqui estamos a considerar a posição ativa do sujeito do conhecimento diante da realidade objetiva, e não propondo um relativismo à moda liberal). Voltamos, então, ao nosso ponto de partida: de que ponto de vista são eles construídos? Tal ou qual ponto de vista não pressupõe 
valores distintos, logo problemáticos, investigação e respostas distintas? Enfim, de acordo com Löwy é preciso reconhecer (e, para ele, Weber o faz em certo sentido) que "na prática, não se pode evitar, impedir ou eliminar a interferência de juízos de valor" (p. 55).

Por tudo isso, acreditamos que, do ponto de vista das opções epistemológicas, esta abordagem sistêmica acaba privilegiando uma postura positivista. Carvalho $(1994$, p. 71$)$ a critica dizendo que tal postura pulveriza, "em nome de uma falsa superação, a dicotomia positivismo versus marxsimo, como se os pressupostos que os geraram (o capitalismo e a crítica acerbada ao "Kapital") tivessem superados" Oliveira (1973), como decorrência política disso, observou que a teoria dos sistemas é uma das possíveis componentes de uma pedagogia do consenso e, para ele, Betti seria um exemplo de autor que a utiliza como fundamento para uma proposta de pedagogia da EF. Desta forma, fica difícil vislumbrar relações mais consistentes, no plano sociofilosófico, entre a proposta de Betti e o discurso sociofilosófico da EF com o qual, no entanto, ele busca contribuir neste estudo.

Pois bem, após estas críticas de caráter político-epistemológico, passemos às críticas de teor marcadamente político-pedagógico.

Inicialmente, pensamos que as alterações didático-metodológicas e sociopsicológicas do modelo de polaridades da prática pedagógica em EF apresentado por Betti, podem ser positivas na medida em que até podem tornar-se um ponto de resistência aos valores dominantes nas aulas de EF. Mas, além desta resistência ou momento 'negativo', não deveria existir um momento 'positivo', próprio do papel da instituição escola, o qual se revela na transmissão/construção de certo saber? Contudo, não fica claro como esta mudança de polaridades se relacionaria com a apropriação, por parte dos alunos, de um saber necessário a uma leitura crítica da realidade? Ou contentaríamos com o momento da resistência?

Prosseguindo suas reflexões no âmbito sociológico-sistêmico, Betti (1992) propõe dois pontos consensuais para a escolha de valores e finalidades a serem expressas numa teoria da EF. Seriam valores e metas respeitantes ao binômio corpo-movimento, pois "a especificidade da EF encontra-se nestes dois conceitos e nas suas inter-relações" (p. 62), e também naqueles respeitantes ao acesso "à cultura corporal de movimento", pois à EF cabe "integrar o aluno à esta esfera da cultura" (p. 
62), para dela usufruir, reproduzi-la e transformá-la. Mas o que seria um sujeito socializado nesta esfera cultural? Quais os critérios teóricos e práticos para tal definição? Como seria, sob esta perspectiva, o currículo de $\mathrm{EF}$, de forma que, ao longo do processo de escolarização, o aluno fosse alcançando tal socialização? E, enfim, como avaliá-la e sob a ótica de qual projeto político-pedagógico?

Tais questões ainda não são contempladas nesta teoria sistêmica que, inclusive, trata de valores e metas no âmbito da cultura corporal de movimento, mas não esclarece qual, afinal, é a radicação político-ideológica destes. Valores e metas podem vincular-se a tal esfera da cultura humana, mas, antes, tem sua radicação histórica nesta sociedade capitalista; são, portanto, valores que exprimem interesses de classe ainda não explicitados pelo autor (novamente uma decorrência política de sua postura epistemológica weberiana?).

Assim, pensamos ser interessante realçar este impasse teórico enfrentado por esta concepção sistêmica: como ela contribuiria para a articulação de uma proposta de sistematização curricular para a EF? Afinal, o nível sociológico é característicamente analítico e descritico, enquanto questões de arranjos curriculares são marcadamente normativas e prescritivas, de forma que uma tal abordagem parece chegar a um ponto-limite exatamente onde deveria começar a sua interface com a pedagogia, i.e., exatamente onde começaria o diálogo entre a razão sociológica e a razão pedagógica. Embora autores como Forquin (1993) façam uma distinção entre estas disciplinas e suas 'razões', outros como Silva (1993a) e Saviani (1993) observam que, na teoria educacional crítica, esta distinção, de fato, inexiste. Parece-nos então que falta a Betti um diálogo com teorias da educação, o que realmente não conseguimos captar na sua proposta. Porém, sabemos que o desenvolvimento de uma concepção pedagógica de EF passa certamente por uma elaboração teórica relativa ao conceito de educação, conforme Kunz (1991).

Outra indagação a se fazer é quanto aos reais efeitos práticos desta abordagem sistêmica. Assim, não deveria Betti ter seguido caminho similar ao do já citado Kunz que, em obra de 1991, tece elaborações teóricas propondo mudanças nos objetivos, conteúdos e métodos de EF e, em trabalho complementar de 1994, realiza experiências de práticas pedagógicas alternativas, buscando unir teoria e prática, denúncia e anúncio? Enfim, sentimos a ausência de uma 'teoria do ensino sistêmica' que 
articulasse de forma mais sistematizada os elementos metodológicos levantados pelo autor. Assim perguntamos: não estaria aqui mais uma evidência da necessidade de uma articulação mais efetiva entre esta 'razão sociológica' e uma suposta 'razão didático-pedagógica' correspondente?

Outra questão diz respeito aos recentes desenvolvimentos na sociologia da educação/do currículo, com estudos de caráter etnográfico e no âmbito da história e sociologia do currículo e de disciplinas escolares, a partir da tradição que se convencionou chamar Nova Sociologia da Educação (Forquin,1993). Isso sem falar no amplo campo de pesquisas em torno de questões como ideologia, poder, cultura, conhecimento escolar, novas tecnologias etc., nos quais a teoria crítica do currículo tem alcançado avanços significativos (Moreira \& Silva, 1994). Desta forma, quem sabe novos desenvolvimentos numa 'sociologia da EF' comecem a buscar aporte teórico-metodológico nesta tradição sociológica, a qual busca relacionar, dialeticamente, as assimetrias de poder na sociedade global e suas relações com as assimetrias de poder no currículo e nas disciplinas escolares, de forma que uma sociologia da EF pudesse de fato relacionar macroestrutura sócio-histórica e microestrutura cotidiana escolar da EF, como foi o propósito de Betti, porém, agora numa perspectiva de estudos ligados à teoria educacional crítica e especificamente ocupada com o cotidiano, com a cultura e com o conhecimento escolar em suas dimensões não objectualizáveis por uma teoria sistêmica.

\section{TEORIA/CONCEPÇÃO SISTÊMICA: COMENTÁRIOS FINAIS OU... PREPARANDO NOVAS POLÊMICAS}

Ao encerrar gostaríamos de não perder totalmente de vista o fato de que a obra em apreço é fruto de determinado momento da história de seu autor e, para o que aqui nos interessa, da própria história da EF. Assim, acreditamos que ela expressa o pensamento político e pedagógico da EF brasileira na virada dos anos 80 para a década atual. Compartilhando das considerações de Oliveira (1993) temos que a pedagogia da $\mathrm{EF}$, nos anos 80, incorporou elementos da ótica do conflito, tão bem representada pela tradição marxista, mas permaneceu presa à hegemonia de uma pedagogia do consenso, de valores liberais e pressupostos epistemológicos positivistas (incluída aí a teoria dos sistemas). De tal 
forma que pensamos que esta abordagem sistêmica reflete bem aquele momento, pois revela-se atravessada, de um lado, pelo propósito sincero de contribuir com o emergente discurso transformador da EF, discurso relacionado a uma pedagogia do conflito; de outro, pelos pressupostos que dão sustentação a sua antagônica, a pedagogia do consenso.

Devido a estas observações, seria oportuno ressaltar que a ideologia dominante - pedagogia do consenso -, por sua origem, é muito mais antiga, mais completamente elaborada e conta com meios de difusão incomparavelmente mais numerosos do que a ideologia socialista-pedagogia do conflito. Por isso, tudo o que significa rebaixar a segunda promove a primeira. E mais: análises como esta que nos propusemos a realizar devem possuir o duplo caráter de incentivo aos debates que têm focalizado a teoria da EF brasileira, visando a enriquecê-los sempre num clima democrático e polêmico, ao mesmo tempo em que devem nos alertar para o fato de que

o fundamental que se deve apresentar frente a esta questão não é que obrigatoriamente todos devem assumir posturas num sentido de superar o capitalismo (e não apenas aperfeiçoá-lo); mas que todos assumam a ousadia de se expor... (Loureiro \& Della Fonte, 1996, p. 184)

E isso nem todos tem feito...

\section{ABSTRACT}

The initial aim of this paper was to report the book Educação Física e sociedade, mainly the systemic conception of physical education. As this article enlarged its limits, it enclosed other productions in the field of "sociology of physical education" with the epistemological, political and pedagogical elements of this theory. We realized that: a) it points out methodological elements which contribute to the critical discourse of physical education; b) it presents characteristics of a critical discourse as well as a conservative attitude; c) it presents a sociological perspective based on a systemic theory with restrictive elements to the development of a "sociology of physical education".

KEY WORDS: Systemic conception, sociology, physical education.

50 Ferreira, M. G. - A teoria/concepção sistêmica: uma perspectiva ... 


\section{NOTAS}

1. Loureiro e Della Fonte (1996) numa crítica a este mesmo autor compartilham desta nossa posição.

2. Trata-se da obra de Buckley, W. A sociologia e a moderna teoria dos sistemas. São Paulo: Cultrix/Ed. USP, 1971.

\section{REFERÊNCIAS BIBLIOGRÁFICAS}

BETTI, Mauro. Educação Física e sociedade. São Paulo: Movimento, 1991.

. Ensino de primeiro e segundo graus: Educação Física para quê?. Revista Brasileira de Ciências do Esporte v. 13, n. 2, 1992.

. Valores e finalidades na Educação Física escolar: uma concepção sistêmica. Revista Brasileira de Ciências do Esporte v. 16, n. 1, 1994.

CARVALHO, Máuri de. O ópio da miséria: uma abordagem política do desporto. Vitória: Universidade Federal do Espírito Santo, 1993.

FORQUIN, J. C. Escola e cultura: bases sociais e epistemológicas do conhecimento escolar. Porto Alegre: Artes Médicas, 1993.

KOSIK, Karel. Dialética do concreto. 6. ed. Rio de Janeiro: Paz e Terra, 1995.

KUNZ, Elenor. Educação Física: ensino e mudanças. Ijuí: Unijuí, 1991. . Transformação didático-pedagógica do esporte. Ijuí: Unijuí, 1994.

LOUREIRO, Robson \& DELLA FONTE, Sandra. Educação Física e sociedade: um diálogo epistemológico. In: FERREIRA NETO, Amarílio (Org.). Pesquisa histórica em Educação Física brasileira. Vitória: CEFD/UFES, 1996.

MÉSZAROS, István. Filosofia, ideologia e ciências sociais. São Paulo: Ensaios, 1993.

LÖWY, Michael. Ideologia e ciências sociais. 10. ed. São Paulo: Cortez, 1995.

MOREIA, A. F. \& SILVA, T. da.. Sociologia e teoria crítica do currículo: uma introdução. In: Currículo, cultura e sociedade. São Paulo: Cortez, 1994.

OLIVEIRA, Vítor M. de. As pedagogias do consenso e do conflito. A produção teórica da educação física brasileira nos anos 80 . Rio de 
Janeiro: Universidade Federal do Rio de Janeiro, 1993. Tese de Doutorado.

SAVIANI, Dermeval. Escola e democracia. 27. ed. São Paulo: Autores Associados, 1993.

SILVA, Tomaz T. da. O que produz e o que reproduz em educação: ensaios de sociologia da educação. Porto Alegre: Artes Médicas, 1992.

- Sociologia da educação e pedagogia crítica em tempos pós-modernos. In: SILVA, Tomaz T. da (Org.). Teoria educacional crítica em tempos pós-modernos. Porto Alegre: Artes Médicas, 1993.

52 Ferreira, M. G. - A teoria/concepção sistêmica: uma perspectiva ... 